\title{
Erratum to: Pulmonary Arteriovenous Malformations Embolized Using a Micro Vascular Plug System: Technical Note on a Preliminary Experience
}

\author{
Emanuele Boatta ${ }^{1}$ - Christine Jahn ${ }^{1} \cdot$ Matthieu Canuet $^{2} \cdot$ Julien Garnon $^{1}$ • \\ Nitin Ramamurthy ${ }^{3} \cdot$ Roberto Luigi Cazzato $^{1} \cdot$ Afshin Gangi $^{1}$
}

Published online: 17 November 2016

(C) Springer Science+Business Media New York and the Cardiovascular and Interventional Radiological Society of Europe (CIRSE) 2016

\section{Erratum to: Cardiovasc Intervent Radiol}

DOI: $10.1007 / \mathrm{s} 00270-016-1493-0$

In the original article the name of the first author was misspelled as "Eanuele Boatta". The correct spelling is "Emanuele Boatta". The original article was corrected.

The online version of the original article can be found under doi:10.1007/s00270-016-1493-0.

Roberto Luigi Cazzato

gigicazzato@hotmail.it

Emanuele Boatta

emanuele.boatta@yahoo.it

Christine Jahn

christine.jahn@chru-strasbourg.fr

Matthieu Canuet

matthieu.canuet@chru-strasbourg.fr

Julien Garnon

juleiengarnon@gmail.com

Nitin Ramamurthy

nitin_ramamurthy@hotmail.com

Afshin Gangi

gangi@unistra.fr

1 Service de Imagerie Interventionelle, Nouvel Hôpital Civil, Hôpitaux Universitaires de Strasbourg, Place de l'Hôpital, 67000 Strasbourg, France

2 Service de Pneumologie, Nouvel Hôpital Civil, Hôpitaux Universitaires de Strasbourg, Place de l'Hôpital, 67000 Strasbourg, France

3 Department of Radiology, Norfolk and Norwich University Hospital, Colney Lane, Norwich NR4 7UY, UK 